\title{
OUTRAS ALEGRIAS: CACHAÇA E CAUIM NA EMBRIAGUEZ MBYÁ-GUARANI
}

Guilherme Orlandini Heurich

Neste artigo exploro os sentidos da embriaguez (-ka'u) proporcionada pelo consumo de cachaça entre os Mbyá-guarani durante as festas que realizam em suas comunidades no sul do Brasil. O foco da descrição está na alteração proporcionada por esse consumo, nas reflexões dos Mbyá sobre os "bailes" e na visibilidade que toma a relação entre vivos e mortos nesse contexto. A partir disso, associo a embriaguez com as cauinagens descritas por etnógrafos de outros povos ameríndios e sugiro que a alteração proporcionada pela cachaça aos Mbyá se assemelha àquelas suscitadas pelas cauinagens.

As comunidades guarani estão localizadas num continuum que vai da Bolívia ao litoral brasileiro, passando também por Paraguai e Argentina, sendo que sua população é estimada em cerca de 180 mil pessoas (ISA 2012). ${ }^{1}$ Um terço dos Guarani vive no Brasil e destes, 7 mil são Mbyá-guarani, os quais ocupam boa parte do território acima referido, notadamente na região de Missiones (Argentina), leste paraguaio e no litoral brasileiro desde o Rio Grande do Sul ao Espírito Santo (Ladeira \& Costa 1995:211). ${ }^{2}$ Ao longo dos séculos, os Guarani se depararam com variadas formas de esbulho e apropriação de seu território - missões, guerras e bandeiras - e se esquivaram delas através de diferentes maneiras de enfrentamento, resistência, aliança e fuga. Tratando especificamente dos Mbyá que moram no sul do Brasil, Garlet e Assis (2004) mostram que a invisibilidade foi durante muito tempo a estratégia utilizada para se aproximar e se afastar dos não indígenas, mas que ela começou a se modificar em meados dos anos 1980, quando os Mbyá passaram a buscar novas relações de aliança, principalmente para a demarcação de suas terras. ${ }^{3}$

A literatura antropológica sobre os Guarani é vasta e, ao longo do século $\mathrm{XX}$, conformou a imagem de um povo fortemente voltado para sua religião, pouco escapando das divindades e do desejo de estar/ser como os deuses. Pissolato (2007:99), por exemplo, constata a construção gradativa de uma percepção dos Guarani como um povo orientado por uma ética religiosa di- 
retamente relacionada às migrações e aos deslocamentos, enquanto Calávia-Saez (2004) salienta essa ênfase na literatura e aponta a ausência relativa de estudos influenciados pela etnologia brasileira e francesa contemporânea, nas quais a alteridade e os "vínculos sociais negativos" são aspectos centrais. ${ }^{4}$ No mesmo sentido, John Monteiro afirma que os estudos históricos sobre os Guarani, quando comparados com trabalho sobre os Tupi da costa no século XVI, apresentam uma abordagem centrada na religião e que difere, assim, da centralidade que tem a guerra na etnologia tupinambá (Monteiro 1998:480-1). ${ }^{5}$

Uma das expressões mais claras dessa sobrecodificação religiosa dos Guarani está no trabalho de Bartomeu Meliá, principalmente na sofisticação que ele faz do conceito de tekó ("modo de ser"), explicitando justamente o aspecto religioso dessa forma de ser e agir (ñande reko marangatu) e salientando que "os Guarani atuais não podem ser entendidos, nem eles mesmos se entendem, se prescindirmos de sua experiência religiosa" (Meliá 1991:9). ${ }^{6}$ A pouca atenção que os bailes de cachaça receberam até recentemente nos estudos sobre os Guarani me parece estar diretamente relacionada à ênfase na religião, principalmente porque a raiva produzida pela embriaguez se contrapõe a esse modo adequado de viver entre os parentes.

Quando estive entre os Guarani, ${ }^{7}$ de forma intermitente, entre os anos de 2005 e 2009 e durante três meses de trabalho de campo em 2010, uma série de acontecimentos deixou claro que era preciso esmiuçar esses comportamentos não adequados — como a embriaguez e a raiva, mas também as narrativas sobre transformações ${ }^{8}$ - e não simplesmente abandoná-los ao estatuto de modos de agir que não se conformam com o ideal da pessoa mbyá-guarani. Pude perceber, assim, que além da inimizade proporcionada pela cachaça, os bailes eram momentos desejados porque propiciavam risadas e encontros amorosos embalados pela música e a dança. A difícil aproximação entre a raiva e o riso é o que chamo de "outras alegrias" e, para dar conta desses momentos e evitar a ênfase na religião - parece importante comparar o que dizem os Mbyá com a etnologia de povos amazônicos que trata de questões como guerra, inimizade e cauinagem. ${ }^{9}$

\section{Outras alegrias}

Para muitos Mbyá, beber cachaça é uma experiência do passado, vinculada muitas vezes a experiências de trabalho fora das comunidades e a sessões de milonga, chamamé e vanerão em pequenos armazéns de beira de estrada. Essas experiências costumam ser contrapostas a uma vida atual afastada dos bailes e próxima das cerimônias realizadas na opy. ${ }^{10}$ Nesses casos, a relação 
entre baile (de cachaça) e cerimônias (na opy) se apresenta de forma diacrônica na trajetória da mesma pessoa, isto é, alguém que bebeu por algum tempo, mas que deixou de fazê-lo à medida que começou a frequentar a opy. Outras narrativas, entretanto, exploram essa dinâmica de forma sincrônica. Altino, ${ }^{11}$ por exemplo, me dizia: "Eu não fumo cachimbo... esse é da parte do karaí [xamã], mas a minha é outra parte". Junto a seu genro, me contavam que "é uma alegria fazer o baile. Só que não é como a alegria da opy, porque lá é outra alegria. Lá na opy fica sentado, fumando cachimbo, cantando e rezando. Mas no baile não. Aí já bebe cachaça, dança forró, mas é alegria também".

Essa diferença entre as duas alegrias - dos bailes e da opy - aparece na oposição entre cachimbo e cachaça, por um lado, e entre canto/reza e dança, por outro. A primeira é uma oposição sensível, digamos, pois contrapõe o frio da fumaça do cachimbo ao calor da cachaça, ${ }^{12}$ visto que as cerimônias realizadas na opy procuram tornar visível a relação entre os Mbya e suas divindades, sendo que o tabaco funciona aí como veículo de comunicação. O que me parece fundamental, porém, é não somente a diferença entre frio e quente, mas também as relações que são mobilizadas nesses espaços, pois se as divindades estão presentes de forma intensa na opy, as conexões que a embriaguez proporciona são de outra ordem, como veremos. ${ }^{13}$

Durante boa parte do meu campo, os bailes aconteceram sempre no mesmo pátio, onde a varanda de uma casa e um galpão em anexo formam um "L". No espaço aberto, um pátio de terra cercado por algumas árvores é iluminado apenas parcialmente pela lâmpada da varanda e pelo fogo de chão aceso dentro do galpão. Além delas, resta a escuridão. Colocado na varanda, virado para o pátio, um aparelho de som é o responsável pelo canto e substitui o xamã - para mantermos a comparação com a opy. A música que se escuta nos bailes é obrigatoriamente estrangeira. Brega, forró, melody e muita cumbia argentina saem das caixas de som durante a noite inteira e o início da madrugada.

Dança-se nos bailes e na opy, mas dançar na opy é bem diferente de bailar cumbia, pois, na primeira, o ritmo que toma a dança é influenciado pelo estilo de música que se escuta, é claro, e essas danças envolvem uma proximidade de corpos que a segunda não requer. Ainda assim, alguns jovens que frequentavam os bailes pela primeira vez, mas que estavam acostumados a ir à opy desde criança, transpunham os passos usados na reza - com o corpo quase imóvel, o pé direito avança e volta ao mesmo lugar, sendo rapidamente seguido pelo pé esquerdo - e tentavam equalizar o movimento dos pés com a proximidade do companheiro de dança.

Além dos passos e do ritmo, a entrada e a saída no pátio para dançar são também interessantes. Assim que as músicas começam a tocar, os pares 
"voam" em direção ao centro do pátio quase todos ao mesmo tempo e saem do pátio na mesma velocidade com que entraram quando a música termina. Enquanto alguns dançam no pátio, outros se mantêm no galpão e jogam monte, um jogo de cartas de ritmo frenético que envolve apostas em dinheiro. Muitos nunca saem dali, de perto do fogo e do jogo, nem para dançar. ${ }^{14}$ Apesar da presença maior de homens nos bailes, as mulheres também os frequentam e, como eles, também se embriagam.

Existem menções aos bailes na literatura sobre os Mbyá e Guarani em geral, sendo que a distinção entre cerimônias religiosas e festas de cachaça entre a opy e os bailes, como disse Altino - é algo mencionado. Nimuendaju (1987 [1914]:14), por exemplo, enfatiza que eram nas festas realizadas para santos cristãos que os Apapokuva bebiam e "toda sorte de excessos" podia ocorrer. Porém, se as brigas não são demasiado intensas, nos diz Schaden (1974 [1954]:179) sobre os Mbyá do Rio Branco, ninguém se arrepende da festa da noite anterior, e salienta que, entre os Kaiowá, as festas de polca paraguaia se estendiam noite a dentro. "A todos nos gusta traguear", dizem os Mbyá de Missiones (Argentina) para Larricq, quando aparecem a embriaguez feminina e a movimentação entre o centro e os extremos do pátio.

Ninguém se privará de dançar, se pode fazê-lo. Para tanto, no setor das mulheres, elas se revezarão para cuidar das crianças pequenas. Ali dormem as crianças visitantes e até mesmo as mulheres, quando vencidas pelo cansaço ou pelo álcool. É ali que serão procuradas pelos homens que as tiram para dançar e para lá voltarão quando a música terminar para esperar a próxima ou comentar, entre risadas - as mais jovens - as características da dança ou de seus companheiros eventuais (Larricq 1993:82-3).

A partir dos anos 2000, o foco das referências sai dos bailes e vai para a embriaguez que começa a aparecer com mais frequência, principalmente em relação aos efeitos negativos que esta causa na desagregação das famílias e na violência intrafamiliar. Macedo (2009:279) e Pissolato (2006:127) notam que a embriaguez está associada a um modo de ser e de agir diretamente ligado ao mundo dos brancos, pois é no retorno da cidade, embriagados, que muitos Mbyá se dirigem - física e oralmente - de forma agressiva a seus parentes. ${ }^{15}$ A relação entre essas duas formas de oralidade - beber e falar - aparece claramente no depoimento da xamã Tatati, que diz que "quando a gente bebe yy tatá ["água de fogo"], a gente vira outra pessoa, fala o que não deve falar, xinga o parente" (Ciccarone 2001:117). Uma reflexão mais detida a respeito da cachaça, entre os Mbyá no Rio Grande do Sul, aparece nos diversos trabalhos publicados por Ferreira (2001a, 2001b, 2003a, 
2003b, 2004, s/d; Ferreira \& Coloma 2005), os quais procuram compreender o processo histórico em que o contato interétnico introduziu o consumo de cachaça e, além disso, como esse processo é visto desde o "conjunto das explicações tradicionais das causas das doenças" (Ferreira 2001a:130). De fato, o trabalho de Ferreira se diferencia dos demais porque coloca a cachaça como um problema central de sua análise. ${ }^{16}$ Mesmo com essa diferença de foco no seu trabalho, Ferreira também revela um elemento interessante sobre a relação entre beber cachaça e ter "experiência".

Outro elemento que os Mbyá apresentaram em suas colocações e que pode levar a pessoa a beber é a sensação de que a cachaça dá "experiência" para aquele que bebe, ou seja, uma pessoa que normalmente não se destaca por pensamentos e colocações sábias pode, ao beber, demonstrar, através do seu discurso, alguns conhecimentos (Ferreira 2003a:15).

A embriaguez como conhecimento aparece também, a meu ver, nas narrativas dos Mbyá a respeito de bebedores famosos do passado. Ao invés de enfatizar as brigas e as consequências das bebedeiras, eles ressaltavam o conhecimento desses velhos embriagados como um contraponto positivo à embriaguez contumaz. Uma dessas histórias exaltava um senhor que, além de beber muito, era um grande cantor: podia ficar horas dentro da opy cantando para as divindades, mas costumava sair no meio das rezas e, do lado de fora da opy, começar a cantar música sertaneja. Outros falavam de um antigo matador, o qual, mesmo dançando, não perdia sua pose, pois bailava como se estivesse desembainhando uma adaga.

Se antes exploramos a diferença entre bailes e opy como uma oposição disjuntiva, a narrativa sobre esse velho bebedor sugere um trânsito mais fluido entre esses dois espaços. A contraposição entre os bailes e a opy aparece aqui quase sobreposta, tal como os pezinhos dos jovens que bailavam pela primeira vez usando os passos da opy. Para compreender essa transitividade entre dois contextos tão diferentes, é fundamental entender o "alegrar-se" $\left(-v y^{\prime} a\right)$ que a fala de Altino apontou. Esta noção foi descrita recentemente por Pissolato (2007) no contexto dos deslocamentos frequentes que famílias e indivíduos mbyá fazem entre as aldeias. A relação entre a alegria e o deslocamento está nos sentidos que - $-\mathrm{y}^{\prime} a$ abrange, pois envolve tanto a diversão quanto a satisfação de estar em algum lugar.

A discussão da autora se insere no tema das migrações e do profetismo guarani, inaugurados por Nimuendaju e desenvolvidos por diversos autores, que não retomarei aqui. ${ }^{17}$ Para a autora, o vy'a é o fundamento que orienta os deslocamentos à medida que a pessoa entende sua condição em certo 
lugar: não se sentir alegre pode, então, implicar um deslocamento para outra aldeia. Permeando a questão da mobilidade e dos deslocamentos está o casamento, ou melhor, as insatisfações que fazem abandonar cônjuges, por um lado, e as conjugações derivadas do que era para ser somente um "passeio". "Migração" e visita seriam, dessa forma, coisas bem parecidas do ponto de vista de quem caminha e, assim, os contextos locais - as aldeias — são nada mais do que configurações provisórias das decisões e das posições das pessoas que ali estão (Pissolato 2007:123-176).

A alegria de um lugar está também nas cerimônias realizadas na opy e, a meu ver, também nos bailes, sendo que a chave que liga ambos os contextos está no humor peculiar dos Mbyá, muitas vezes exacerbado pela embriaguez. As piadas que se contam são tanto sobre histórias pessoais, recentes ou não, quanto sobre as ocorridas com outros: rir de si mesmo, das bobagens que já se fez, mas também das gafes que outros cometem. Aquele que conta a história é obrigado a rir, quase forçando os outros a acompanhá-lo: contentamento que se extrai - se espreme - dos ouvintes: contar a mesma piada inúmeras vezes, durante horas, e rir ainda mais alto a cada vez que é contada. Muitas das histórias/ piadas que se conta, além de tudo, são mentiras completas. Inventa-se muita coisa, só pra fazer o outro rir, ou também para passar um conhecimento - tal como um senhor que ficou cinco horas falando, em um encontro de jovens, sobre a multiplicidade de mentiras que aconteceram em sua vida, tentando ensinar algo para os menores. Há uma arte, inclusive, de desenvolver uma risada particular, própria de cada um, bastante pronunciada, a ser ouvida de longe: escutando aquele gargalhar idiossincrático, outros saberão quem está por alegrar-se.

\section{Sentidos da embriaguez}

A alteração que a embriaguez proporciona fica evidente em situações que frequentemente ocorrem nos bailes de cachaça. Cansado de dias seguidos de festa, fui conversar com Moreno, que não gostava muito de bailar e preferia ficar sentado na beira do fogo. No caminho de minha casa até a dele, encontrei algumas pessoas. Adriano tentava ficar em pé enquanto dois meninos acenavam com a mão pedindo ajuda e, ao mesmo tempo, procuravam agarrá-lo pelos braços. Foi um caminho difícil até a casa de Moreno (irmão de Adriano) não somente pelo capim alto que precisamos atravessar, mas também por suas quedas constantes. Trocávamos palavras e piadas, o clima era bom; ríamos juntos e seguíamos. Com esforço, chegamos até sua casa e o colocamos sentado debaixo de uma árvore. Ele estava visivelmente sem 
forças. Sua mãe chegou e, de repente, ele se levantou e vociferou na direção dela: "Eu vou te matar"! Quando tentou agarrar o cabelo dela, segurei-o pelos braços e ela pôde escapar, mas não foi muito longe. De dentro da casa, Moreno vinha caminhando em nossa direção, mas não parecia muito preocupado com a situação. Chegou tranquilo e nos convidou para sentar.

Seu irmão parecia estar novamente sem forças, mas retomou-as logo que chegou perto do fogo e, agarrando uma tora em chamas, partiu novamente para cima de sua mãe, chamando-a de feiticeira. Moreno agarrou firme o seu braço, fazendo-o derrubar a tora e logo segurou ambos os pulsos de Adriano em direção ao chão: com calma, voltaram os dois em direção ao fogo e sentaram. Enquanto enrolávamos um primeiro cigarro, Adriano levantou-se e correu para dentro de casa, seguido por seu irmão. Fiquei sentado, perto o suficiente para saber que bastante coisa estava sendo destruída. Logo saíram, aproximaram-se do fogo e Adriano sentou-se novamente. Chorou um pouco mais, falando mal de sua mãe, mas Moreno não parecia dar muita bola. Adriano tentou se apoiar atrás, mas o banco virou e ele caiu estatelado de costas na terra, mas somente o tempo suficiente para se recompor, entrar novamente na casa e quebrar algumas outras coisas. Moreno entrou com ele, mas Adriano despistou-o lá dentro e, na saída, tendo seu irmão ficado um pouco para trás, conseguiu agarrar outra tora em chamas e, na hora em que tentou jogá-la na direção de sua mãe, Moreno agarrou-o por trás fazendo o corpo de Adriano girar e desviando o trajeto da tora, que terminou por espatifar-se no chão.

O pai de Adriano, sua nova esposa e sua filha pequena passaram pelo pátio em que estávamos sentados, pois estavam saindo da opy. Olharam de soslaio para a cena, mas seguiram em frente, sem dizer uma palavra. "É difícil. Às vezes me dá vontade de bater nele, mas acho que é pior. Ele quebrou a TV ao meio" - disse Moreno.

A narrativa fala por si, mas quero explorar alguns momentos dessa cena. Primeiro, há o próprio comportamento de Adriano, ou seja, a embriaguez em seu auge, com os rompantes de raiva intercalados com expressões curtas de alegria, misturados com fases de choro intenso. Houve as piadas feitas ao longo do caminho, mesmo com o cambalear do corpo, assim como o desejo de destruir e matar outros corpos, com toda a vontade que lhe era possível. Enfim, a capacidade de alternar, em pouquíssimo espaço de tempo, o conversar-tranquilo ao redor do fogo e o virar-intenso com as chamas. Além dos sentidos que toma a embriaguez, aqueles que não estavam embriagados se colocavam numa relação de distanciamento e jocosidade, que aparecia também sob a forma de silêncio. Moreno, diante de seu irmão, não queria escutar suas palavras e não se esforçava nem um pouco na comunicação. Parecia não escutar 
ou, pelo menos, não lhe dirigiu a palavra em nenhum momento, deixando-o falar sozinho. A mãe deles, mesmo atacada, não tentava dar ao filho qualquer explicação diante de suas acusações e intenções agressivas. Por outro lado, tampouco se afastava da cena - ainda que fugisse das toras em chamas que quase a atingiam - e mantinha-se ali, por perto, observando e fumando seu cachimbo. Em outros momentos, a atitude era tratá-lo jocosamente: muitos faziam piadas, outros faziam perguntas que qualquer embriagado jamais saberia responder, e outros ainda pediam para que dançasse, rindo alto da performance. Há aqueles que gostam de provocar os tombos dos bêbados, incentivando ações difíceis que os fazem cair. De maneira geral, a indiferença ou a jocosidade é a forma de lidar com a embriaguez alheia.

Contudo, há momentos em que os braços do bêbado precisam ser contidos e seguros em direção ao chão. Nessas situações, diz-se que a pessoa está "dona-da-raiva" (ivai já) e essas cenas afastam muita gente dos bailes. A raiva que manifestam quando estão - $k a^{\prime} u$ (embriagar-se) não é uma simples exacerbação de sentimentos pessoais ou uma gestualização de desejos reprimidos - formulações que poderíamos usar para compreender Adriano quando ele diz "vou te matar" ou "você é uma feiticeira". ${ }^{18}$ A raiva opera através das conexões que a embriaguez proporciona, principalmente porque, ao estreitar a relação com os mortos - e com outros seres que também são "donos da raiva" - ela faz com que a pessoa veja seus parentes como não parentes.

\section{Cachaça não tem parente}

A cachaça não tem amigo e quer trazer a pessoa para junto dela: "a cachaça não tem irmão, não tem família. Cachaça não tem parente". Escutava esta frase sempre que conversava com alguém sobre o beber. Diziam também que a pessoa, quando bebe, esquece seus amigos e não lembra quem são seus parentes. Essa formulação da embriaguez em termos de esquecimento tinha, a meu ver, o objetivo de traduzir para o meu mundo aquilo que os Mbyá experienciam quando se embriagam. Aparentemente, a formulação parece sugerir a nossa (ocidental, neobrasileira) compreensão espontânea da bebedeira como aquilo que nos faz esquecer das coisas, do sofrimento e dos amores perdidos. Contudo, não são esses sentidos que os Mbyá estão sugerindo quando a formulam dessa maneira, pois é preciso relacionar esse esquecimento com a ideia de que a cachaça é um vetor de antiparentesco, isto é, ela não tem parente. Primeiro, isto mostra a solidão em que vive a cachaça e seu desejo de se aproximar de alguém e de seduzi-lo. Tal forma 
de agir, no entanto, não é característica apenas da cachaça, pois é dessa maneira que também se comportam os espectros dos mortos, os ãgue.

A pessoa mbyá-guarani, ao morrer, deixa por aqui seu aspecto terreno (ã), o qual se torna ãgue (lit. ex-ã) e passa a vagar por esta terra. Os rituais funerários incluem, além de cantos para que a alma do defunto encontre o caminho das divindades (Schaden 1974 [1954]:133), o sepultamento de forma a evitar o contato do cadáver com a terra e a construção de uma pequena choça de palha sobre a sepultura (H. Clastres 1968:65). A cada oito dias, me contava Daniel, é preciso verificar a sepultura e perceber se há alguma alteração, pois qualquer fenda ou abertura significativa na terra é sinal de que o morto está se transformando - em onça, veado ou outros seres - e, neste caso, é necessário abrir a sepultura, retirar o cadáver e queimá-lo. Estando frio, convém fazer um fogo de chão e, durante um bom tempo, é preciso colocar água num pote próximo à sepultura, caso tenha sede o morto.

Estando sozinha, a cachaça procura alguém, busca um parceiro e o seduz pela embriaguez. Age, dessa forma, da mesma maneira que agem os ãgue ${ }^{19}$ que estão sempre em busca de uma proximidade com os vivos, pois não conseguem esquecê-los. Ocorre que a cachaça não age somente como os mortos, pois atrai estes últimos para perto dos vivos-bêbados e os faz virar-mortos. Os Mbyá dizem que o grande problema é que os mortos querem aumentar o grupo deles e, através da cachaça, procuram seduzir os vivos a agirem com eles e como eles. Por isso, o bêbado passa a proceder como eles e, assim, quer também trazer outros vivos para o seu coletivo.

Garlet (1997) relata que o mbogua seria a ex-alma telúrica, que pode aproveitar-se das viagens que o ñe'ë faz durante o sonho para entrar no corpo de uma outra pessoa, deixando-a triste e doente. ${ }^{20}$ Quando a pessoa morre, o mbogua fica vagando: assobiando e chorando para atrair as pessoas e "quem escuta é sinal de que está sendo escolhido" (Garlet 1997:171) — e talvez por isso, na narrativa que trouxe acima, Moreno não tenha dado ouvidos a seu irmão Adriano. Se entre os Wari' (Aparecida Vilaça em comunicação pessoal) é necessário falar com alguém excessivamente embriagado para trazê-lo de volta ao convívio tranquilo com seus parentes, o que os Mbyá enfatizam é exatamente o contrário, isto é, o imperativo de evitar qualquer forma de comunicação.

No mesmo sentido, mas em relação aos mortos, os Mbyá dizem que não se deve lembrar muito do morto, muito menos falar o nome dele, ainda que tais precauções se refiram somente aos parentes mais próximos, os quais, afetados pela tristeza que a morte dos parentes lhes causa, muitas vezes decidem se mudar. $\mathrm{O}$ esquecimento envolve também o abandono de todos os objetos referentes aos mortos, "porque o mboguá (espírito do morto), 
que continua sendo o dono dos objetos, poderia causar a morte" (Schaden 1963:86). ${ }^{21}$ Garlet (1997:173) aponta que o mbogua pode "disfarçar-se de animal e atrair as pessoas", o que nos remete ao comentário de Daniel sobre a necessidade de ficar de olho na sepultura. ${ }^{22}$ Assim como os ãgue, os bebedores são caminhantes noturnos, ao contrário dos que ficam em casa e dormem cedo. Os ãgue vagam noite adentro e, na época intensa de bailes que passei na aldeia, essa forma de agir parecia contagiar até uma das xamãs: "Até minha avó, que não bebe nunca, já tá começando a ficar como os $k a^{\prime} u$. Ela agora fica caminhando por aí durante a noite", dizia-me um de seus netos.

O devir-morto do embriagado mbyá aparece também na etnografia de Assis (2006) e novamente a relação é perpassada pela questão da "experiência" que a cachaça proporciona a quem a bebe. Assim, uma liderança que bebia muito, mas ao mesmo tempo era reconhecida como grande xamã, levava seus parentes a acreditar que seus poderes, na verdade, derivavam de sua relação com os angue. Embriaguez e experiência, nesse sentido, se misturam com a saudade, atração e perigo que os angue fazem a pessoa sentir.

Dentre os perigos do angue está o de tentar atrair seus parentes para a morte. O perigo da tristeza e da saudade advém de uma premissa de que tais sentimentos não são gerados pela própria pessoa que o sente. A lembrança do morto é o seu angue agindo em seus parentes para que eles tenham tais sentimentos e desejem morrer (Assis 2006:142).

A relação entre vivos e mortos, do ponto de vista dos vivos, procura construir uma separação discursiva e espacial dos angue, enquanto estes últimos, por outro lado, procuram se aproximar e incutir nos vivos a vontade de deles se lembrarem. E aqui, como vimos, a cachaça se coloca como uma espécie de veículo que aproxima vivos e mortos. Ferreira $(2001,2003)$ menciona essa conexão e diz que a cachaça abre caminho para os angue, pois os mortos, ao vagarem pela terra, vêm beber com os vivos.

Noção similar à de ãgue é o angwêry, do qual os Nhandeva têm um verdadeiro pavor, principalmente porque há uma estreita ligação com o esqueleto do defunto (Schaden 1974 [1954]:90). Entre os Kaiowá, os angwéra são abundantes, onipresentes e, em sua maioria, provêm de fantasmas de Kaiowá mortos. O uso do fogo era comum para mantê-los afastados e, além disso, ninguém se aventurava a andar à noite, pois esta era especialmente temida (Watson 1952:40). Saindo um pouco mais da esfera mbya, Cadogan afirma que a "alma telúrica" dos Guayaki é designada iãvé, tendo o angué guarani como seu equivalente: "cabe acrescentar que iãvé, a 'alma telúrica' 
do Guayaki se converte, tal como a alma telúrica do Guarani, em um fantasma perigoso que obriga a abandonar a acampamento após a morte de um membro adulto do grupo" (Cadogan 1967/1968:141). ${ }^{23}$ Fundamental aqui é esquecer os que se foram, pois a lembrança e a saudade fariam com que desejássemos partir juntamente com os falecidos. É preciso apagar seus traços, como se fosse possível riscar da memória, destruir o passado particular dos que se vão.

\section{Donos da raiva}

É difícil encontrar nas etnografias sobre os Mbyá qualquer aspecto "positivo" na relação com os angue. Pissolato (2007:266) ressalta, por exemplo, que os sonhos com os mortos não geram cantos ou enviam almas aos vivos tal como ocorre entre os Nhandeva e que a aparição de mortos nos sonhos é sempre algo preocupante. ${ }^{24}$

Ausência de qualquer aspecto positivo talvez não seja a melhor maneira de colocar a questão. Como afirmou Calávia-Saez (2004), uma das características da etnologia americanista recente é explorar justamente esses "vínculos sociais negativos", tais como a guerra, a inimizade e, poderíamos incluir aqui, a relação com os mortos e a embriaguez pela cachaça. Há ainda um aspecto da etnografia mbyá que é preciso acrescentar nessa relação entre embriaguez e morte, a saber, o comentário que alguns mbyá fazem sobre os bêbados como pessoas "donas da raiva" (ivai ja). Estar com raiva é, certamente, estar próximo aos angue, contudo, não são somente eles que proporcionam esse modo de agir e quero explorar brevemente as conexões entre os angue e outros seres "donos da raiva".

Sigo aqui Helene Clastres, que nos diz que angue precisa ser afastado dos vivos porque traz uma ameaça: o tupichua. A partir de informações recolhidas entre os Mbya, afirma que o tupichua é o "princípio vital da carne crua", o qual também está no sangue. Tupichua pode aproximar-se da pessoa e transformá-la em jaguar: o caçador mesquinho e solitário, comendo sozinho na floresta, atrai inevitavelmente tupichua.

Nesse caso, com efeito, tupichua pode frequentemente tomar a aparência de uma bela mulher, enfeitada com pinturas atraentes; ela faz perder a razão; diz ela: "vamos fazer esta coisa". Se é feita "esta coisa" (isto é, a copulação), logo ela começa a cobrir-se de manchas e já aparece diferente de uma mulher, põe-se a unhar a terra e a rosnar; e também sua vítima se põe a unhar a terra e a rosnar... (H. Clastres 1978:93). 
A autora sugere que o tupichua, além de apresentar-se como jaguar sedutor, também está presente na mitologia, principalmente no conjunto de mitos de Sol e Lua, em que o comportamento dos jaguares motiva a tentativa dos irmãos de eliminá-los. ${ }^{25}$ A raiva dos jaguares e seu comportamento remetem, na mitologia, a um personagem muito evocado pelos Mbyá: anhã. A conjunção entre esses personagens aparece, por exemplo, no trabalho de Franz Muller, no qual a devoração da Lua por um jaguar ou cachorro cf. Montoya (1985 [1639]:53) — é mencionada:

A mitologia dos Mbyá marca Tupã como vencedor do aguara (isto é, do jaguar negro), que os Mbyá consideram uma encarnação de Aña. O jaguar, ou Aña, devora a Lua e o Sol [...] um ser malvado que está em contraposição à Tupã, mas que não pode contra ele. Aña como os corpos dos mortos (Muller 1989 $[1930]: 19,23) .^{26}$

Há uma característica, nesse conjunto de personagens, que oscila entre a sedução e a devoração, ou talvez justamente a sedução para a devoração, como o jaguar que se transforma em mulher para seduzir um caçador, mas também o anhã que devora a Lua e consome o corpo dos mortos. Ao incluir os ãgue nesse conjunto, sugiro que essa devoração pela sedução remete ao desejo da cachaça de se aproximar dos vivos, fazê-los esquecer dos seus parentes e passarem a agir como os mortos. Um pouco como o jaguar sedutor - que vira mulher para fazer com que o caçador vire onça - a cachaça vira ãgue para fazer com que os vivos virem mortos.

\section{Cachaça e cauim}

Essa linha de conexão entre mortos e outros seres "donos da raiva" através da embriaguez pela cachaça entre os Mbyá remete a certos contextos etnográficos. Refiro-me aos trabalhos sobre cauinagens ameríndias, principalmente amazônicas, nas quais a morte e os mortos são centrais: a identificação progressiva entre matador e vítima, entre os Araweté (Viveiros de Castro 1986, 1992); a morte causada pelo cauim e os mortos que, saudosos dos vivos, são tomados por inimigos pelos Yudjá (Lima 1986, 2005); e a associação entre a chicha consumida nas festas e a carne consumida durante o ritual funerário wari' (Vilaça 1992). Assim, quero agora traçar algumas aproximações e distanciamentos entre esses contextos etnográficos e a experiência da embriaguez entre os Mbyá. ${ }^{27}$

Entre os Araweté, por exemplo, as cauinagens têm um forte idioma de guerra, principalmente nas músicas cantadas durante a festa: quem canta é 
o inimigo, não o cantador. As palavras alheias do cauim alcoólico remetem aos mortos e a esse processo de devir-Outro experimentado intensivamente pelo matador, mas também por toda a coletividade. A reverberação dos pontos de vista, cantados após o homicídio, é o resultado desse processo de identificação entre matador e vítima: o morto fala pela boca do matador. Homens e matador unificam-se para cantar os cantos recebidos por este do inimigo que foi morto. Contudo, isto tem um preço, pois o matador nunca mais será o mesmo: identificado com o inimigo morto, passa a ser uma pessoa de quem se desconfia, de cujo corpo a raiva pode emergir a qualquer momento. O matador torna-se um inimigo para os outros araweté e, assim, o espírito da vítima nunca o deixa: ambos vão conjuntamente para o céu, onde não são devorados pelos Maï, passando somente pelo banho da imortalidade.

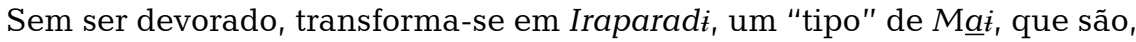
na verdade, os Outros — inimigos — dos Ma $\underline{i}$ :

[...] ele é imediatamente um inimigo, ou uma fusão ambígua entre bide e awĩ: em outras palavras, ele já é um Mại. Se o xamã é um morto futuro, o matador é um futuro deus: ele incarna a figura do Inimigo e o ideal de ser araweté (1992:246).

A figura do matador, enquanto ideal da pessoa araweté, permite divisar um cogito canibal, o qual coloca em jogo uma situação cuja verdade está no Outro e em tempo diverso. Destino da pessoa araweté, a alteridade está, desde sempre, prefigurada na própria pessoa e o canibalismo, aqui, não visa a uma incorporação das propriedades do outro: não é um movimento narcisístico, mas sim uma alteração.

Em certo sentido, então, é como se a cachaça fosse "igual" ao cauim araweté na medida em que a alteração proporcionada pela embriaguez mbyá torna visível essa relação com os angue. Poderíamos pensar que, entre os Araweté, os mortos são inimigos mortos, enquanto entre os Mbyá os angue são os mortos do próprio grupo. Contudo, o termo angue nunca identifica uma pessoa em especial e se refere aos mortos enquanto grupo, isto é, como coletivo de mortos (Heurich 2011). A diferença, neste caso, estaria menos na relação entre parentes e inimigos e mais entre um indivíduo e um coletivo, mas mesmo assim a distinção é elidida, visto que os Araweté chamam o inimigo de awï na'owe, uma categoria genérica semelhante aos angue.

A forma particular da alteração proporcionada pela embriaguez aparece claramente na etnografia yudjá, na qual também os mortos são personagens centrais. ${ }^{28} \mathrm{~A}$ embriaguez produz um sentimento - münho - que vai do leve mau-humor até o ódio, e inclui também a indiferença. Münho é o oposto de kariá - alegria - e, se os Yudjá bebem pela alegria, pois com ela cantam, 
namoram e falam muito, münho pode também irromper nas bebedeiras. Traduzido por "brabo" ou "briga", tal sentimento ocorre quando se está bêbado, mas também durante a guerra e faz do bom guerreiro aquele "que sabe usar a embriaguez guerreira como razão do ato de violência, sem cambalear, completamente certeiro" (Lima 1986:06). Ao mesmo tempo em que a alegria aumenta coletivamente, pode começar a ser minada por dentro, pois em algumas pessoas a alegria se torna raiva.

A raiva não é uma experiência coletiva e não é bonita. A cauinagem não é um ritual de negação da sociedade por ela mesma [...]. Mas esta aventura, que é coletiva, tem ainda outros riscos: é demasiado estreita a fronteira entre os Outros em que os Juruna se tornam e o inimigo em que um deles pode se tornar. O grupo assim, paradoxalmente, mantém prontidão para defender-se do que ele próprio busca: a elevação da sociabilidade a limites extremos, o cume da sociabilidade em que consiste a embriaguez (Lima 1995:422).

As considerações de Lima (1995) sobre a possibilidade de a raiva emergir num contexto de alegria me remetem ao comentário de Altino, no início deste artigo, sobre o baile como uma "outra alegria". Se a comparação dele, naquele momento, era entre o baile e a opy, a inversão dos termos nos permite passar de uma "outra alegria" para uma "alegria Outra", em que a busca pela satisfação no beber envolve, em certo grau, um virar-angue que corre o risco de deslindar em raiva. Entre os Yudjá, esse devir-Outro se expressa na alteridade que é o próprio cauim, pois ele é pessoa, tem corpo e possui um sabor forte e amargo que mata (embriaga) os homens: pessoa produzida por um homem e uma mulher e oferecida ao grupo; consumida ("matada"); com uma alma que vai aos mortos; cujo resto apodrecido é exposto, cozido e consumido. Como diz Lima, "a pessoa é homóloga ao cauim" (1995:413). Como vimos, o que distingue a cachaça dos vivos é sua solidão, pois enquanto o movimento entre parentes é fundamental entre os Mbyá, a cachaça é uma ameaça porque não possui parentes. Nesse sentido, a cachaça se distingue do cauim yudjá na medida em que não é uma pessoa: a cachaça é justamente uma força de antiparentesco que visa, através da embriaguez, fazer com que as pessoas esqueçam dos seus parentes trazendo-os para o grupo dos mortos.

Lembrando um pouco a história de Adriano (supra), os convidados do hüroroin wari' entram na aldeia gritando sugestões de relações sexuais com as mulheres anfitriãs, pouco antes de invadirem as casas da aldeia que os recebe, por vezes quebrando algumas coisas. A chicha está presente em três festas wari', mas é no hüroroin que ela se torna mais evidente. Essa festa começa quando um mensageiro é enviado para outra aldeia para chamar seus 
moradores para a celebração e, nesse meio tempo, os anfitriões preparam o tronco para armazenar a chicha (Vilaça 1992). ${ }^{29}$ Inversamente à embriaguez mbyá, porém, essa invasão precede a embriaguez, pois os convidados wari' são repelidos pelos anfitriões e sofrem a imposição de beber grandes quantidades de chicha. Panelas são emborcadas diretamente e, para continuar bebendo, é preciso vomitar: desses que bebem, vomitam e desfalecem se diz que estão mortos. Por isso, quando entram nesse estado de rigidez e inconsciência - dito itam - precisam ser levados a uma casa, onde ficarão até serem despertados no dia seguinte (Vilaça 1992:185-192).

A chicha oferecida evoca, além da lógica das trocas matrimoniais, o canibalismo funerário wari', pois tanto a primeira quanto o segundo estão inseridos numa lógica de duplo-cozimento, ainda que invertidos: mastigação cultural e fermentação natural, na chicha; putrefação natural, assar cultural, no repasto funerário. A chicha evoca os ritos funerários, pois "o jam do morto bebe chicha azeda no mundo subterrâneo, exatamente como os convidados do hüroroin" (Vilaça 1992:201). ${ }^{30}$ Beber chicha entre os Wari' é ser predado como mostra a reação dos anfitriões, no hüroroin, aos convidados após terem suas casas invadidas - e também é predar, pois a chicha consumida está diretamente associada à carne consumida no ritual funerário. ${ }^{31}$ Nesse sentido, o que me parece saltar aos olhos nas três etnografias é a centralidade da inimizade e dos mortos. As palavras alheias do cauim alcoólico araweté remetem aos inimigos mortos e a esse processo de devir-Outro experimentado intensivamente pelo matador. A morte e os mortos aparecem, nas cauinagens yudjá, como sentidos dessa embriaguez que chega ao cume da socialidade, apresentando a difícil imbricação entre a alegria enquanto motivadora das festas e a raiva enquanto limite sempre possível.

Por fim, Lima (1995) menciona brevemente que a embriaguez produz um estado de espírito que leva à dança, momento de celebração de afinidades e produção de relações fictícias de afinidade potencial e alteridade: os homens, por exemplo, usam o português para falar entre si. Diversas vezes presenciei os Mbyá falarem português quando embriagados, o que poderia nos levar a uma reflexão sobre a relação dos Mbyá com os não indígenas. Deixo esta possibilidade para uma outra oportunidade, mas quero usar esse pequeno comentário de Lima (1995) para pensar aquela que talvez seja a grande diferença entre a cachaça e o cauim: sua origem. ${ }^{32}$ Se o ponto principal das páginas precedentes foi tentar estabelecer conexões com a etnologia amazônica e dizer, com elas, que a cachaça é como se fosse cauim, há algo que distancia a cachaça do mundo da cauinagem. A preparação de fermentados alcoólicos a partir do milho, da mandioca e outros envolve uma série de restrições, prestações e formas específicas em seu consumo. Os preparados de mandioca, talvez pela 
elaboração mais breve (um a dois dias), podem ser ingeridos quase cotidianamente, mas a preparação do cauim alcoólico a partir do milho é um processo mais demorado (cerca de 20 dias). A cachaça, especificamente nesse sentido, se diferencia completamente do cauim, pois não é sazonal e está, digamos, sempre disponível para o consumo. Essa disponibilidade está relacionada, a meu ver, com outro aspecto que diferencia as cauinagens dos bailes de cachaça, a saber, a presença feminina nas bebedeiras enquanto bebedoras e não como produtoras do que está sendo consumido.

\section{Considerações finais}

Seguramente os Mbyá com quem convivi diriam que ka'u reko - "estar embriagado" - é um comportamento tido como "antissocial", isto é, "anti-teko". Contudo, os bailes e as bebedeiras ocorrem, seguem ocorrendo e as razões dessa "antissociabilidade" foi o que tentei compreender aqui. Para tal, lancei mão da expressão "outras alegrias", apoiado na fala de um mbyá, a qual expressa a alegria que ocorre nos bailes, alimentada pela embriaguez, buscada por muitos e que, particularmente, se opõe à alegria proporcionada pela casa cerimonial, como disse seu Altino. Por outro lado, como vimos, é sempre possível que momentos de raiva venham a emergir e, nesse sentido, a alegria contém a raiva como seu duplo semântico e sensível: a raiva é o outro da alegria. Nesse sentido, as outras alegrias são sempre alegrias-outras, nas quais os mortos aparecem como o sujeito primordial dessa alteração que boas festas sabem proporcionar.

A literatura sobre os bailes começa com pequenas referências que salientam a embriaguez feminina, a relação com festas estrangeiras e os excessos que a bebida proporciona. Excessos que se tornam violência física e verbal nas referências mais recentes sobre a embriaguez, que também pode ser associada ao conhecimento através da experiência. A esses temas, quis acrescentar uma certa dimensão de alegria nas piadas que se contam e na sedução que envolve os bailes. Fundamentalmente, os bailes são celebrações diferentes daquelas realizadas pelos xamãs, pois o que está em jogo não são as divindades: as conexões são outras. Há uma diferença grande, enfatizada pelos Mbyá, entre as celebrações que acontecem na casa cerimonial para se aproximar das divindades — nas quais o veículo primordial é a fumaça do cachimbo - e as festas programadas para dançar forró, cantar como os brancos e aproximar-se dos mortos - nas quais a cachaça proporciona a comunicação. Os bailes, além disso, ocupavam o espaço que os xamãs guarani costumam ocupar - a noite - e, por diversas vezes, escutei comparações entre 
as atividades do xamã e aquelas dos que estão embriagados. Por exemplo, os relatos de iniciação xamânica salientam que o afastamento dos bailes e da cachaça é fundamental para o processo de aprendizado. Não se consegue escutar os cantos enviados pelas divindades quando se frequenta intensamente os bailes e se está embriagado. Nesse sentido, enquanto contraponto do xamã, o estado $k a^{\prime} u$ remete justamente aos mortos, inimigos e suas armas.

Se os bailes proporcionam momentos intensos de alegria e festa, a comunicação que se estabelece com os ãgue pode acabar em raiva e agressividade contra os próprios parentes. Esquecendo os parentes, a pessoa acha que é sozinha e, assim, seus parentes deixam de escutá-la, ignorando suas ações até onde é possível, mas evitando que algo pior aconteça. A raiva e a agressividade enquanto comportamentos antissociais são, nesse sentido, comportamentos anti-humanos. Por um lado, distanciam-se da atitude apropriada para com os parentes e são uma forma de ausência de respeito. Por outro lado, aproximam-se dessa forma de agir que é particular dos mortos, tal como os vivos os concebem: os ãgue querem aumentar o grupo deles e esforçam-se para tal. Avizinham-se dos vivos para levar outras pessoas daqui e, enquanto isso, estes se esforçam para esquecê-los. Ao mesmo tempo, ao embriagar-se, a pessoa pode acabar ignorando que os vivos são seus parentes. Diante de sua mãe, o filho não a percebe como parente; tomando-a por um inimigo, tenta agredi-la.

A embriaguez, em seu auge, é uma forma de alteração na qual a pessoa aproxima-se dos espíritos dos mortos e toma os seus parentes por contrários. Desde o ponto de vista dos inimigos, vê os seus próprios parentes como inimigos e, assim, busca predá-los. Se essa predação raramente se consuma durante as cauinagens - ou seja, são poucos os que morrem - entendo que o ponto é delinear o espaço simbólico em que ela se apresenta. Assim, diferentes figuras que encarnam o jaguar foram aparecendo ao longo da análise, tendo nos ãgue uma imagem fundamental: os espíritos dos mortos que se insinuam durante os bailes. Os inimigos, assim, não são apenas uma alteridade, espelho a partir do qual se constitui o interior da sociedade, mas sim coletivos com os quais há também uma troca: uma troca de posições que a embriaguez proporciona.

Que os mortos e a raiva sejam constitutivos dessa experiência da embriaguez pouco implica uma necessidade de combatê-la ou encerrá-la, mas apenas de mantê-la reservada a alguns momentos especiais, evitar que ela se torne cotidiana. Desejar o fim da alteração pessoal e da celebração das diferenças entre vivos e mortos é algo que, a meu ver, escapa da forma pela qual os Guarani pensam os bailes e a cachaça: manter sua distância dos vivos e impor respeito aos mortos, claro, mas nunca erradicar a relação. 
Recebido em 02 de setembro de 2014

Aprovado em 10 de outubro de 2015

Guilherme Orlandini Heurich é doutorando em antropologia social pelo PPGAS/

MN/UFRJ. E-mail: <guiheurich@gmail.com>.

\section{Notas}

${ }^{1}$ Os grandes grupos guarani contemporâneos que habitam esse amplo território são os Chiriguano, Mbyá, Kaiowá (conhecidos no Paraguai como Pãi-Tavyterã) e os Nandeva (ou Avá-Guarani).

${ }^{2}$ Há certa controvérsia no levantamento de dados sobre o número exato da população guarani, visto que a mobilidade de indivíduos e coletivos ao longo desse território é constante, isto é, há sempre a possibilidade de que pessoas sejam contadas mais de uma vez ou não contadas por não estarem no local durante o recenseamento. Essa mobilidade, por vezes entendida como "excessiva" ou "prejudicial" por parte das autoridades, faz parte da "dinâmica social" dos Guarani, como ressaltaram Ladeira (1992:6; 2001:38) e Garlet (1997) - mobilidade, aliás, que não é recente (Monteiro 1998:477). Além dos estados brasileiros citados acima, cabe mencionar que há aldeias ou coletivos guarani junto a comunidades de outros povos no Maranhão, em Tocantins (Ladeira 1992:24) e Pará.

${ }^{3}$ Dentre as principais formas que tomava essa invisibilidade, os autores mencionam a "ocupação de áreas caracterizadas como terras públicas, ocultando suas casas cerimoniais, protegendo suas crianças e mulheres do olhar do branco, vestindo-se como pessoas da sociedade englobante e se relacionando com elas como se fossem um grupo marginal qualquer ou índios sem identidade - ou aculturados, como ainda são identificados pelo senso comum" (Garlet \& Assis 2004:40).

${ }^{4}$ Fausto (2005), por sua vez, revisando a literatura histórica e antropológica sobre os Guarani, aponta como os conceitos de cultura e tradição - de cultura tradicional, digamos - utilizados pela etnologia sobre os Guarani "tenderam a depurar e a denegar qualquer transformação em nome de um núcleo duro e puro da religiosidade guarani" (:392). Para uma discussão das considerações de Fausto sobre o xamanismo guarani, ver Macedo (2009:285).

${ }^{5}$ Monteiro (1998:481) afirma também que a antropofagia tem pouco destaque na bibliografia guarani, cujas fontes históricas foram compiladas por Chase-Sardi (1964). 
${ }^{6}$ A noção de tekó, salvo engano, tem sua origem na etnografia de Meliá, Grünberg e Grünberg (1976) sobre os Pãi-Tavyterã no Paraguai. Este tema foi largamente desenvolvido na etnologia sobre os Guarani.

${ }^{7}$ Não especifico aqui onde realizei meu trabalho de campo porque o tema da embriaguez pela cachaça é delicado e pode ser usado maldosamente para reforçar preconceitos antigos em relação aos povos indígenas, sendo que um dos objetivos deste artigo é justamente colaborar para uma compreensão menos preconceituosa e enviesada da questão.

${ }^{8}$ Transformações denominadas -jepota, as quais foram trabalhadas recentemente por Macedo (2013).

${ }^{9}$ No que tange à ampla bibliografia sobre os Guarani, me permito não revisá-la inteiramente aqui, primeiro porque excederia os limites e os objetivos deste artigo e, mais importante, porque detalhadas revisões da mesma já existem, como, por exemplo, no trabalho de Elizabeth Pissolato (2007:97-122), e também na articulação que faz Viveiros de Castro (1986:81-127) dessa bibliografia com as questões centrais de outros grupos tupi-guarani.

${ }^{10}$ A opy é a casa onde se realizam os rituais xamanísticos mbyá-guarani. A palavra já foi traduzida por "casa de rezas", "casa de orações" e "casa cerimonial", sendo que adoto aqui o último destes termos.

${ }^{11}$ Os nomes usados neste artigo foram recriados em português, mas todos se referem a pessoas mbyá.

${ }^{12}$ A fumaça (tataxiná) do cachimbo (petynguá) é fria, entre outras coisas, por sua associação com Jakaira, divindade mbyá-guarani que espalhou sua "bruma vivificante" sobre a terra ainda em seus primórdios (cf. Cadogan 1992 [1959]).

${ }^{13}$ A fumaça do cachimbo e a alegria que a opy proporciona é central, por exemplo, na descrição que faz Montardo (2009:126-136) dos rituais mbyá, pois os instrumentos musicais são esfumaçados com o cachimbo logo após a entrada de todos na opy. A alegria, por sua vez, surge com os cantos do xamã, pois "ao contrário de um ethos pessimista apontado na literatura como característico dos Guarani, o que observamos na letra desses cantos é um convite à alegria" (Montardo 2009:131).

${ }^{14}$ Franz Müller, em seu trabalho sobre os Guarani de Missiones, comenta os extremos a que o jogo de cartas pode chegar: "Os homens jogam apaixonadamente, com vigor e dedicação dignos de qualquer um, o jogo de cartas tomado da civilização, com apostas relativamente altas. Ocorre com certa frequência que um indígena perca, em uma noite, todos os seus bens: espingarda, facão, suas roupas e as de sua mulher" (Müller 1989 [1930]:84).

${ }^{15}$ Cf. Assis (2006:129-130) para uma narrativa semelhante. 
${ }^{16}$ Ao mesmo tempo, o trabalho procura dialogar com outras áreas, principalmente com a saúde pública, e também nesse sentido se diferencia dos trabalhos citados anteriormente, pois concebe a pesquisa como um processo de intervenção que visa "eliminar os problemas do alcoolismo entre a população indígena" (Ferreira \& Coloma 2005:181). A noção de alcoolismo é usada nos trabalhos de saúde pública, epidemiologia e psicologia (ver, por exemplo, Guimarães \& Grubits 2007; Maciel et alli 2012), sendo que a aplicabilidade do conceito vem sendo repensada e discutida - conforme diversos artigos em Ministério de Saúde (2001). O que minha etnografia entre os Mbyá sugere é que a noção de alcoolismo talvez não seja o melhor caminho para compreender a embriaguez indígena, visto que $\mathrm{ka}^{\prime} u$ (-embriagar-se), como veremos, é pensado como uma forma de ser e agir, isto é, como um estado que pode ocorrer a qualquer um e não tanto como uma "doença", isto é, como uma condição do indivíduo, tal como o uso da noção de alcoolismo parece sugerir. No mesmo sentido, creio eu, o trabalho de Ferreira (2001a, 2001b), assim como as reflexões de Langdon (2001), sustentam que é preciso contextualizar o que de fato significa alcoolismo entre os povos indígenas. Para um estudo minucioso sobre as abordagens antropológicas e de saúde pública sobre o uso de cachaça entre os povos indígenas, cf. Caux (2011).

${ }^{17}$ Para uma recensão recente desses autores, bem como uma inflexão interessante sobre a noção de profetismo, ver Sztutman (2012).

${ }^{18}$ A relação entre a cachaça e a raiva aparece brevemente no trabalho de Vieira (2009) sobre os Maxacali.

${ }^{19}$ Como veremos adiante, os ãgue também são chamados de mbogua pelos Mbyá.

20 "[A] segunda alma (de origem telúrica, mas não de alma animal), os Mbyá designam com o nome de teko achy kue, cuja tradução é 'o produto de vida imperfeita' [...] Entre os Mbyá, o teko achy kue se converte em mbo-gua, fantasma também muito temido, e também chamado angue, nome que em guarani clássico significa alma de defunto" (Cadogan 1952:33).

21 “Entre os Mbüa disseram-me que os bens materiais do defunto continuam sendo propriedade do seu mboguá, razão pela qual ninguém os pode herdar. O mboguá viria buscar quem deles se apropriasse. Confessou Pablo Vera, de Yroysã, que às vezes algum velho fica com os objetos do morto, porque de qualquer jeito terá de morrer dentro de curto prazo" (Schaden 1974 [1954]:134).

22 "Por sua vez, há um número de seres invisíveis que poderíamos chamar, segundo nosso conceito, fantasmas e que são considerados como almas vagabundas dos mortos [anguéry] ou que se apresentam como seres metamorfoseados em animais ou plantas" (Muller 1989 [1930]:106). E também: "ao morrer, esta alma [ou angue] fica na terra e pode incorporar-se em algum animal e/ou torna-se espírito 'maligno' que deseja levar a alma de seus parentes e amigos para 'não ficar sozinho'" (Meliá, Grunberg \& Grunberg 1976:256). 
${ }^{23}$ Cadogan (1967/1968) indica que o sufixo vé é o equivalente do guarani -kué, que, além de indicarem pretérito, também significam "o produto de, a consequência de, sendo utilizado para expressar ideias abstratas" (:141).

24 "Os Mbya não concebem, como os Kaiowa ou os Nhandeva, um lugar celeste habitado por aqueles que já teriam antes vivido na Terra, como o ma'etirõ kaiowa controlado pelo deus Tupã Arasa (Meliá, Grünberg \& Grünberg 1976:234) ou o ñe'ëng-güery, o 'país dos mortos' ava-katu-etê, onde estão as almas-palavras que aguardariam nova oportunidade de 'reencarnação' (Bartolomé 1991 [1977]:89). Em sonhos, mortos mbya não enviam almas nem cantos como fariam os Nhandeva (Nimuendaju 1987 [1914]:77; Schaden 1974 [1954]:112-113)" (Pissolato 2007:266).

${ }^{25}$ A tentativa dos irmãos Sol e Lua de acabar com os jaguares - mba'e ypy, os "seres primitivos" - fracassa: a fêmea grávida que conseguiu escapar "teve um filho macho, que copulou com a mãe, e sua progenitura espalhou-se por toda a terra. Deve-se a isto, conclui o mito, que hoje existam jaguares" (Clastres 1978:95).

${ }^{26}$ Numa etnografia recente, Mello (2006:256-7) descreve os planos cósmicos e menciona a "terra dos anhã", ressaltando a capacidade predatória e atrativa desses seres, bem como o perigo de ser iludido e capturado por eles. A autora aponta ainda que anhã é responsável pela devoração periódica de Jaxy, a qual pode ser vista pelos humanos a cada lua minguante e durante os ecplises. Chariã seria ainda uma outra designação a incluir entre os "donos da raiva", visto que está frequentemente associado a anã, mas deixo de fazê-lo aqui com receio de citar em excesso. Ainda sobre os anhã, mas saindo dos Mbyá, o próprio Muller menciona que a mitologia Pãï-tevyterã diz que a morada dos Añáy - "um grande lagoa de água fervente" (Muller 1989 [1930]:30) - está acima de nós, onde ela agarra as almas dos mortos que estão a caminho da morada dos deuses. Meliá et alii (1976), por sua vez, dizem que a Lua "tinha vontade de ir a uma festa e como, naquele momento, somente os añáy fizeram uma, foi embora com eles" (:231). Chamorro (2004), por exemplo, tratando da mitologia guarani, afirma que "em relatos recentes, esses Añang são identificados com outros seres humanos, inimigos dos Guarani, tal como os Kaingang, Guaicurus e os 'brancos'" (:127). Por fim, Cadogan (1962), também falando dos Pãï, fala da existência de um kagui járy - "dono da cerveja" - que pode ser chamado de Taviangusú, mas também de Añay, pois "são sinônimos" (:80).

${ }^{27}$ Sair do contexto guarani é sobretudo um movimento que partiu de minha experiência entre os Mbyá, tal como afirmei no início deste artigo. Meu objetivo é traçar conexões de forma a "expor" a etnografia a outros contextos ameríndios e, quem sabe, poder olhar a embriaguez mbyá desde o ponto de vista amazônico. Os trabalhos de Sztutman $(2003,2006)$ foram importantes na elaboração dessa visada comparativa, mas privilegio aqui apenas os trabalhos de cunho etnográfico.

${ }^{28}$ Há um lugar em que os Yudjá, certa vez, escutaram algumas galinhas e, depois de gritarem sem obter resposta, pensaram se tratar das galinhas dos mortos. A alma da yacuha - nome do fermentado alcoólico elaborado pelos Yudjá - viaja para esse lugar 
ao final de uma bebedeira entre vivos, quando começa então uma bebedeira entre os mortos. Entretanto, se os vivos bebem a alma e o líquido, os mortos se satisfazem apenas com a primeira (Lima 1986).

${ }^{29}$ Para a festa, mulheres de diferentes casas pilam o milho até obter uma pasta fina e uniforme, para então misturá-lo com água. Aos poucos, partes desse mingau são maceradas, usando-se as mãos ou a boca, e depositadas novamente na panela. Essa produção descentralizada vai sendo reunida no grande tronco, que deve estar cheio para a chegada dos convidados (Vilaça 1992:200).

30 "O jam é um traço, marca, representação ou imagem de um corpo" (Vilaça 1992:55). Cf. Vilaça (2005) para um desenvolvimento da noção de jam, tendo como fundo a reflexão sobre pessoa partida na Melanésia, bem como sobre teorias amazônicas de corporalidade, xamanismo e parentesco.

31 "O oferecimento da chicha azeda é um equivalente simbólico da devoração canibal, ou seja, os convidados são castigados pelos anfitriões, 'transformados em presa'" (Vilaça 1992:202).

${ }^{32}$ A relação entre os Mbyá e os não indígenas aparece em diversos autores e também a explorei em meu trabalho de campo. Não as retomo aqui porque a conceitualização mbyá da embriaguez e da cachaça nos remete principalmente aos mortos, como espero ter mostrado neste artigo. Para o assunto, ver Assis (2006), Garlet (1997), Gobbi (2008), Ladeira (1992, 2001), Larricq (1993), Macedo (2009), Pissolato (2007) e Pradella (2009), entre outros.

\section{Referências bibliográficas}

ASSIS, Valéria. 2006. Dádiva, mercadoria e pessoa: as trocas na constituição do mundo social Guarani. Porto Alegre: PPGAS/UFRGS.

BARTOLOMÉ, Miguel Alberto. 1991. Chamanismo y religion entre los ava-katu-ete. Assunción: Biblioteca Paraguay de Antropologia, Universidad Católica.

CADOGAN, Leon. 1952. "El concepto guarani de alma: su interpretación semántica". Folia Linguistica Americana, 1(1):31-34.
- 1962. "Aporte a la etnografia de los guarani del Amambái, Alto Ypane". Revista de Antropologia da USP, 10(1-2): 43-92. . 1965a. "Especulaciones en torno al Bai Ete Ri Va Guayaki". America Indigena, XXV(3):304-318.

. 1965b. "En torno al BAI-ETE-RI-VA y el concepto guarani de NOMBRE". Suplemento Antropologico, 1(1):3-13. . 1967/68. "Chonó Kybwyrá: aves e plantas en la mitologia guarani". Revista de Antropologia, 15-16:133-147. 
1992 [1959]. Ayvu rapyta. Assuncion: Biblioteca Paraguaya de Antropologia.

CALAVIA-SAEZ, Oscar. 2004. "La persistencia guarani: introducción". Dossiê Guarani. Revista de Indias, LXIV(230):9-14. - 2006. O nome e o tempo dos Yaminawa. São Paulo: Edunesp/Nuti.

CAUX, Camila Becattini Pereira de. 2011. Histórias de cachaça e povos indígenas. Dissertação de Mestrado, PPGAS/ MN/UFRJ.

CHAMORRO, Graciela. 2004 . "La buena palabra: experiencias y reflexiones religiosas de los grupos guaraníes". Revista de Indias, LXIV(230):117-140.

CHASE-SARDI, Miguel. 1964. "Avaporu. Algunas fuentes documentales para el estudio de la antropofagia Guaraní". Revista del Ateneo Paraguayo, 3.

CICCARONE, Celeste. 2001. Drama e sensibilidade: migração, xamanismo e mulheres Mbya-guarani. Tese de Doutorado, PUC-SP.

CLASTRES, Helene. 1968. "Rites funéraires guayaki". Journal de la Societé des Americanistes, LVII:62-72.

- 1978. Terra sem mal: o profetismo tupi-guarani. São Paulo: Brasiliense.

DELEUZE, Gilles. 1981. Aula sobre Spinoza. Disponível em: http://www.webdeleuze.com/php/texte.php?cle=38\&grou pe $=$ Spinoza $\&$ langue $=2$ Acesso em 04/12/2015.

DIETLER, Michal. 2006. "Alcohol: antropological/archeological persperctives". Annual Review of Anthropology, 35: 229-49.

FAUSTO, Carlos. 2005. "Se Deus fosse jaguar: canibalismo e cristianismo entre os Guarani (séculos XVI a XX)". Mana, 11(2):385-418.

FERNANDES, João Azevedo. 2011. Selvagens bebedeiras: álcool, embriaguez e contatos culturais no Brasil Colonial (Séculos XVI-XVII). São Paulo: Alameda.

FERREIRA, Luciane Ouriques \& COLOMA, Carlos. 2005. "Approche intraculturelle destinée à réduire les dommages liés à la dépendance à l'alcool chez les Mbya-Guarani du Rio Grande do Sul, au Brésil". Drogues, Santé et Société, 4(1):175-216.

FERREIRA, Luciane Ouriques. 2001a. Mba'e achÿ: a concepção cosmológica da doença entre os Mbyá-Guarani num contexto de relações interétnicas. Dissertação de Mestrado, POA, PPGAS/UFRGS. . 2001b. "Relatório etnográfico da I Reunião Geral dos Karaí, caciques e lideranças Mbyá-guarani sobre o uso abusivo de bebidas alcoólicas e alcoolismo" - RS. POA, CIPSI. Mimeo. . 2003a. "As 'boas palavras' dos Xondaro Marãgatu como alternativa para a redução do consumo de bebidas alcoólicas entre os Mbyá-Guarani-RS". V Reunião de Antropologia do Mercosul, Florianópolis. Mimeo.

. 2003b. "A pessoa Mbyá-Guarani e a emergência da 'cultura do beber': as múltiplas causas do beber e as consequências desencadeadas pelo uso abusivo de bebidas alcoólicas - RS". V Reunião de Antropologia do Mercosul, Florianópolis. Mimeo.

· 2004. "O 'fazer antropológico' em ações voltadas para a redução do uso abusivo de bebidas alcoólicas entre os Mbyá-Guarani no Rio Grande do Sul". In: J. Langdon \& L. Garnelo (orgs.), Saúde dos povos indígenas: reflexões sobre antropologia participativa. Rio de Janeiro: Associação Brasileira de Antropologia/ Contra Capa. pp. 89-110.

- s/d. "O impacto do uso abusivo de bebidas alcoólicas sobre a pessoa Mbyá-guarani-RS". Mimeo.

GARLET, Ivori. 1997. Mobilidade mbyá: história e significação. Dissertação de Mestrado, PPG História/PUCRS. · \& ASSIS, Valéria. 2004. "Análise sobre as populações guarani contemporâneas: demografia, espacialidade e questões fundiárias". Revista de Indias, $\operatorname{LXIV(230):35-54.~}$ 
GUIMARAES, Liliana \& GUBRITS, Sonia 2007. "Alcoolismo e violência em etnias indígenas: uma visão crítica da situação brasileira". Psicologia \& Sociedade, 19(1):45-51.

GOBBI, Flávio Schardong. 2008. Entre parentes, lugares e outros: traços na sociocosmologia guarani no Sul. Porto Alegre: UFRGS. Dissertação de Mestrado. 116pp.

HEURICH, Guilherme Orlandini. 2011. Outras alegrias: respeito e bailes mbya. Dissertação de Mestrado, PPGAS/MN/UFRJ.

ISA. 2012. "Guarani". Povos Indígenas no Brasil. Disponível em: http://pib. socioambiental.org/guarani. Acesso em 01/10/2014.

LADEIRA, Maria Inês \& COSTA, Carlos Zibel. 1995. "Ageografia mítca guarani-mbyá. A concretitude físico social do mundo (território) guarani-mabyá e os espaço mítico que o contém". In: Milton Santos (org.), O novo mapa do mundo: problemas geográficos e um mundo novo. São Paulo: Associação Nacional de Pós-graduação e Pesquisa em Planejamento Urbano e Regional. pp. 209-214.

LADEIRA, Maria Inês. 1992. "O caminhar sob a luz": território mbya à beira do oceano. Dissertação de Mestrado, PUC/SP. - 2001. Espaço geográfico guarani-mbya: significado, constituição e uso. Tese de Doutorado, Programa de Pós-Graduação em Geografia Humana, Faculdade de Filosofia, Letras e Ciências Humanas, USP. LANGDON, Esther Jean. 2001. "O que beber, como beber e quando beber. $O$ contexto sociocultural do alcoolismo entre as populações indígenas". Anais do Seminário sobre Alcoolismo e DST/AIDS entre os Povos Indígenas Brasília, DF. Mimeo.

LARRICQ, Marcelo. 1993. Ypytuma: construcción de la persona entre los Mbya-Guarani. Posadas: Editorial Unversitaria.

LIMA, Tânia Stolze. 1986. A vida social entre os Yudjá (índios Juruna). Dissertação de Mestrado, PPGAS/MN/UFRJ.
1995. A parte do cauim: etnografia juruna. Tese de Doutorado, PPGAS/MN/UFRJ. 2005. Um peixe olhou pra mim: o povo Yudjá e a perspectiva. $1^{\mathrm{a}}$. ed. São Paulo/Rio de Janeiro: ISA/Editora Unesp/NuTI.

MACEDO, Valéria de Mendonça. 2009. Nexos da diferença: cultura e afecção em uma aldeia guarani na Serra do Mar. Tese de Doutorado, FFLCH/USP. - 2013. "De encontros nos corpos guarani". Ilha, 15(1/2):180-207.

MACIEL, Silvana Carneiro; OLIVEIRA, Rita de Cássia Cordeiro de \& MELO, Juliana Rízia Félix de. 2012. "Alcoolismo em indígenas potiguara: representações sociais dos profissionais de saúde". Psicol. Cienc. Prof., 32(1): 98-111.

MELIÁ, Bartomeu. 1991. El guarani: experiencia religiosa. Asunción: Biblioteca Paraguaya de Antropologia, Vol. XIII CEADUC - CEPAG.

MELIÀ, Bartolomeu; GRUNBERG, Friedl \& GRUNBERG, Georg. 1976. Los Pai-Tavyterã - etnografia guarani del Paraguay contemporaneo. Asunción: Centro de Estudios Antropológicos. Universidade Católica Nuestra Señora de la Asunción.

MELLO, Flávia. 2006. Aetchá Nhanderukuéry Karaí Retarã: entre deuses e animais: xamanismo, parentesco e transformação entre Chiripá e Mbyá Guarani. Tese de Doutorado, IFCH/UFSC. MINISTERIO DA SAÚDE. 2001. Anais do Seminário sobre Alcoolismo e DST/ AIDS entre os Povos Indígenas. Brasília, DF. Mimeo.

MONTARDO, Deise Lucy. 2009. Através do mbaraká: música e xamanismo guarani. São Paulo: Edusp.

MONTEIRO, John Manuel. 1998 [1992]. "Os Guarani e a história do Brasil meridional: séculos XVI-XVII". In: M. Carneiro da Cunha (org.), História dos índios no Brasil. São Paulo: Companhia das Letras/ Fapesp. pp. 475-498. 
MONTOYA, Antonio Ruiz de. 1985 [1639]. A conquista espiritual feita pelos religiosos da Companhia de Jesus nas províncias do Paraguai, Paraná, Uruguai e Tape. Porto Alegre: Martins Livreiro Editor.

MÜLLER, Franz. 1989 [1930]. Etnografia de los Guarani del Alto Paraná. Buenos Aires: Societatis Verbi Divini.

MURA, Fabio. 2006. A procura do "bom viver": território, tradição de conhecimento e ecologia doméstica entre os Kaiowa. Tese de Doutorado, PPGAS/UFRJ.

NIMUENDAJU, Curt. 1987 [1914]. As lendas da criação e destruição do mundo como fundamento da religião dos Apapocúva-Guarani. São Paulo: Hucitec/Edusp.

PISSOLATO, Elizabeth de Paula. 2006. A duração da pessoa: mobilidade, parentesco e xamanismo mbyá (guarani). Tese de Doutorado, PPGAS/MN/UFRJ. - 2007. A duração da pessoa: mobilidade, parentesco e xamanismo mbyá (guarani). São Paulo/Rio de Janeiro: ISA/Editora Unesp/NuTI.

PRADELLA, Luis Gustavo de Souza. 2009. Entre os seus e os outros: horizonte, mobilidade e cosmopolítica guarani. Porto Alegre: UFRGS/PPGAS. Dissertação de Mestrado.

SCHADEN, Egon. 1974 [1954]. Aspectos fundamentais da cultura guarani. São Paulo: Edusp.

. 1963. "Caracteres específicos da cultura mbüa-guarani". Revista de Antropologia, 11(2).

SZTUTMAN, Renato. 2003. "Comunicações alteradas: festa e xamanismo na Guiana". Campos, 4: 29-51.

2006. De outros caxiris: festa, embriaguez e comunicação na Amazônia indígena. Versão para publicação de Dissertação de Mestrado defendida em 2001 no PPGAS da USP. - 2012. O profeta e o principal: a ação política ameríndia e seus personagens. São Paulo: Edusp.
VIEIRA, Marina. 2009. "Virando Inmõxã: uma análise integrada da cosmologia e do parentesco Maxakali a partir dos processos de transformação corporal". Amazônica, 1(2): 308-329.

VILAÇA, Aparecida. 1992. Comendo como gente: formas do canibalismo Wari'. Rio de Janeiro: Editora da UFRJ/Anpocs. - 2005. "Chronically unstable bodies". Journal of the Royal Anthropological Institute, 8(2): 445-464.

VIVEIROS DE CASTRO, Eduardo. 1986. Araweté: os deuses canibais. São Paulo: Zahar/Anpocs. - 1992. From the enemy's point of view. Chicago: University of Chicago Press. VOGT, P. Federico. 1903. La civilización de los Guaraníes en los siglos XVII y XVIII. Buenos Aires: Imprenta de Guadalupe.

WATSON, James. 1952. "Cayuá culture change: a study in acculturation and methodology". American Anthropological Association, memoire number 73. 


\section{Resumo}

A partir de trabalho de campo realizado entre os Mbyá-guarani, este artigo procura compreender os sentidos que toma a embriaguez proporcionada pelo consumo de cachaça, focando na descrição dos Mbyá sobre a alteração e os "bailes", bem como na relação entre a cachaça e os espectros ãgue. Lanço mão da expressão "outras alegrias" que descreve a alegria proporcionada pelos bailes e pela embriaguez, principalmente em oposição à alegria experienciada na "casa cerimonial" (opy). Mostro, por outro lado, que as "outras alegrias" precisam ser pensadas também como "alegrias-Outras", pois quando a embriaguez se torna raiva contra os próprios parentes, os mortos aparecem como o sujeito primordial dessa alteração que a cachaça proporciona. Por fim, associo a embriaguez de cachaça a etnografias sobre cauinagens de outros povos ameríndios, sugerindo aproximações e diferenças com esses contextos. Para os Mbyá, a embriaguez é uma forma de alegria e também de alteração, na qual a pessoa se aproxima dos espíritos dos mortos e pode, no limite, tomar os seus parentes por contrários.

Palavras-chave Mbyá-guarani, Festa, Embriaguez, Cachaça.

\section{Abstract}

This article describes how the Mbyáguarani understand the drunkenness caused by sugar-cane spirit (cachaça). I focus on the Mbyá description of drinking behaviour in their bailes (feasts) as well as in the relationship of cachaça to the spirits of the dead (águe). I use the expression "other joys" in order to describe the happiness of the Mbyá during their feasts in opposition to the happiness that is experienced in the ceremonial house (opy). However, the idea of "other joys" has an immediate counterpart in that of "joyous-otherness", for when drinking leads to excessive and violent behaviour towards kinspeople, the dead emerge as primordial figures in the alteration that cachaça enables. The relationship of the Mbyá-guarani experience with cachaça is then compared to other Amerindian ethnographies where maize beer (cauim) is drunk, revealing both similarities and differences. For the Mbyá-guarani, drinking cachaça is a joyous experience that can result in alteration, bringing the spirits of the dead closer to the living, who thereby risk seeing their kinspeople as foes.

Key words Mbyá-guarani, Feast, Drunkenness, Sugar cane liquor. 